\title{
CHALLENGES FOR THE TRAINING OF HEALTH PROFESSIONALS THROUGH INTERNATIONAL UNIVERSITY PARTNERSHIPS
}

\author{
Aneta Dokova \\ Department of International Relations, Medical University - Varna, Bulgaria.
}

\section{SUMMARY}

Purpose: The purpose of the paper is to summarize the experience of the participants in the collaboration for international training of health professionals, find out the challenges and learn lessons about the perspectives of similar partnerships in Bulgaria, and more specifically, in Medical University "Prof. Paraskev Stoyanov" of Varna (MU-Varna).

Material and methods: A good practice for academic networking in the field of public health and nursing care of the international public health partnership is analysed. The partnership combines teaching activities at a local level and distantly in order to encourage the collaborative teaching and learning. The activities at a local level include summer schools, workshops and seminars and are associated with exchange and face-to-face communication between students and teachers.

Results: The development and the maintenance of successful and sustainable international partnerships is difficult, time and resource consuming. The challenges associated with them result from the diversity of the participating partners in terms of cultural, political, geographical and economic context. The human, structural and information technology resources are available at MU-Varna together with experience in negotiations and intercultural dialogue. The comparative analysis suggests that similar partnerships can be applied by other universities with the relevant experience and resources at hand for the provision of training for different health professionals.

Conclusion: The lessons of the international public health network have considerable implications for the future training partnerships at medical universities. MUVarna is prepared to take part in such trainings with partner universities and institutions in order to enhance the international cooperation for academic training in the fields of public health and nursing care through university partnerships.

Keywords: academic partnerships, health professionals, internationalization, training, medical students, health professionals

\section{INTRODUCTION}

Training in the field of nursing care needs to be conceptualized from a global perspective since the problems in public health, and their solutions have global determinants and consequences. The international university partnerships have the potential to maintain this perspective through the enhancement of academic cooperation, exchange and communication between academic institutions beyond national borders.

A good practice for such academic networking in the field of public health and nursing care is presented by the International Public Health Partnership (IPHP) - a collaboration between the School of Public Health at Bielefeld University, Germany, the Centre of Social Medicine and Community Health at Jawaharlal Nehru University in New Delhi, India, the Department of Public Health at Bashkent University in Ankara, Turkey which was later joined by the Department of Languages and Linguistics at the University of Maiduguru in Maiduguru, Nigeria [1]. The partnership is established in 2005 and was aimed at facilitating the information exchange, nurturing the discussion for the transferability of terminology in public health, contributing to the structural development of the participating institutions and promoting intercultural dialogue through the combination of on-site teaching activities with distance learning. Although this kind of mixed learning was well accepted by both students and teachers, they encountered various obstacles associated mainly with the limited external funding, insufficient own financing, time and staff resources along with contradicting legislation and structures for educational degree programmes at the location of the partnerships.

\section{PURPOSE}

The purpose of the paper is to summarize the experience of the participants in the collaboration for international training of health professionals, find out the challenges and learn lessons about the perspectives of similar partnerships in Bulgaria, and more specifically, in Medical University "Prof. Paraskev Stoyanov" of Varna (MU-Varna).

\section{MATERIAL AND METHODS}

We analysed the experience of the partners to this IPHP, learned the lessons for joint teaching and made some 
recommendations for the other universities which are involved in partnerships with higher medical schools or universities and which are interested in developing such partnerships.

Based on the study of the good practice of IPHP [1] reported in international literature, we aimed at summarizing the experience of the participants in the collaboration for international training of health professionals, finding out the challenges and learning lessons about the perspectives of similar partnerships in Bulgaria, and more specifically, in Medical University "Prof. Paraskev Stoyanov" of Varna (MU-Varna).

The main objective is to improve the structural basis of the teaching in international health care, extend the understanding of the multi- and interdisciplinary foundation of the teaching and the initiatives for health care, facilitate the information exchange and start a discussion about the transferability of the terms in public health and nursing care between partner institutions [1]. The various activities in this partnership were targeted at providing students and lecturers with possibilities to experience and analyze together the international aspects of health care, the ethical implications, the responsibilities of the stakeholders, the policies and the strategies for diminishing the global and local problems faced in public health care.

\section{RESULTS AND DISCUSSION}

\section{IPHP experience}

The students from Nigeria, India and Turkey were given the opportunity to benefit from a first-hand experience with health problems and limitations faced by the German health system and take an informed part in the debate for public health priorities. On the other hand, the German students took advantage of their exposure to public health problems in a poorer environment which is eyeopening for them and help them to better understand public health. Any cooperation has to involve the participants on an equal footing in order to grow into a partnership between higher schools. It includes not only a unilateral exchange between developed countries (Germany) and developing regions (Turkey, Nigeria and India). The exchange in the other direction is also equally important as regards the teaching of the political and economic aspects of health, the comparative analyses of the health systems and the linguistic issues associated with health/nursing care provision - areas in which the other partners have special expertise [1].

The partnership combines teaching activities at a local level and distantly in order to encourage the collaborative teaching and learning. The activities at the local level included summer schools, workshops and seminars and were associated with exchange and face-to-face communication between students and teachers. These activities were complemented with electronic media serving as a platform for distance learning and electronic communication between students and instructors.

Having studied in-depth the experience of the International Public Health Network, we tried to assess the previous experience and the possibilities available at the MU-Varna to train specialists in the field of nursing care and public health in partnerships.

Since 2007, the Department of International Relations has been set up as a structure of MU- Varna, which is responsible for the establishment and maintenance of international partnerships and the conclusion of bilateral, trilateral, and since recently, multi-lateral agreements for academic cooperation aimed at facilitating the development in various specific areas of training and research. Some of the active partnerships have proved to be successful and sustainable as they are measured by concrete outcomes and benefits. Since 2012, the Coordination office of "Erasmus" programme has been an indispensable part of the Department. Throughout the years of its functioning, significant experience has been accumulated, and the mobilities for student and academic staff exchange have been increasing with every year. One of the good practices of the Department of International Relations is the involvement of the students in hosting incoming international students, the development and the maintenance of the students' website and the organization of numerous activities, including on-line conferences, meetings and training.

Perspectives for the training of health professionals at MU-Varna in partnership with other universities and training organisations

MU-Varna has experience in teaching a joint Master's programme in healthcare management jointly with First Moscow State Medical University (Russia) and is currently developing a Master's programme in pharmacy. In partnership with other Russian partners from the Medical Centre for Ayurvedic Therapy, the Centre for Eastern Medicine at MU-Varna organised the first training in Ayurveda, during which Indian specialists conducted a theoretical course in Ayurveda and made demonstrations in diagnostics and treatment of some of the most common and socially significant diseases. The possibilities are being discussed for a distance-learning course for the training of health care specialists.

Beside the partnership of MU-Varna with AO Foundation in Davos (Switzerland) in the fields of implantology, maxillofacial surgery, orthopedics and traumatology, negotiations are underway for the training of specialists in nursing care and, more specifically, for orthopedic nurses. Joint teaching is being discussed, similar to the one provided within the International Public Health Network, for continuous training of nursing care specialists envisaging blended learning, e.g. combined face-face and distance teaching.

Information technology is crucial for this type of learning, and MU-Varna already has in place special IT infrastructure along with a department for e-learning and distance learning who provide continuous IT support to the teaching/learning processes, on-line lecture courses and tests. The learning platform for distance learning and testing and the electronic communication between academic staff and students which mixes on-site and distance 
learning has been functioning for over 5 years and has been operating without significant hitches.

Last but not least, is the experience gathered throughout the 57-years' from its foundation, in the training of international students of other cultures and religions. They have been treated on an equal footing with the native students, have equal rights and MU-Varna educates its staff and disciples in a spirit of tolerance and respect to diversity.

As already emphasized, the presence of already established structures is of paramount importance for the training in international partnerships. The human, structural and information technology resources are available together with experience in negotiations and intercultural dialogue.

The analysis of the available structures, resources and IT at MU-Varna suggests that there are prerequisites for the establishment of international partnerships for training in the fields of public health and nursing care.

Lessons reported from academic training partnerships in the fields of public health and nursing care

The development and the maintenance of successful and sustainable transnational partnerships can be difficult, time and resource consuming. The challenges associated with them result from the diversity of the participating partners in terms of cultural, political, geographical and economic context. In this light, we present some of the lessons of the International Public Health Network which have implications for the future training partnerships at MU-Varna.

Partnerships have to be based on mutual trust, open communication, equality and commitment. In a similar way, the expectations of every partner in the cooperation must be clear from the outset for the rest. The collaboration must set specific and measurable goals, which have to be documented in writing in a memorandum of understanding or an agreement. They are important for the evaluation of the partner activities and are crucial for the quality management.

The regular face-to-face or on-line meetings are necessary for the coordination and planning as well as to ensure that the activities are implemented properly, and the participants stay focused on the objectives of the partnership.

Partnerships which envisage the use of distance learning activities have to take into account the high requirements associated with the IT infrastructure, including broadband connections which are not always reliable in the developing countries. Our German colleagues warn that the distance learning activities based on real-time exchange, for instance, lectures transmitted simultaneously in several universities, can bring to disappointing results. Instead, they recommend using asynchronic activities using for example podcasts, which are far more flexible and can be easily adapted to the concrete on-site conditions and course structures for each partner. The continuous IT support, for example for the internet site administration, is absolutely necessary.
The distance learning activities have to follow the low-threshold approach so that they can be easily adopted by both lecturers and students. In addition, all participants should be actively involved in the development of the partnership in order to enhance their motivation and commitment. In the International Public Health Network, the students play an active role in the development and the maintenance of the website of the partnership, the organization of the on-line activities and the hosting of the exchange students.

Structural development is also necessary to prevent the partnership from dependency on the individual commitment of certain members of the academic staff. The turnover of the academic staff is common in higher schools, and therefore, the actions and outcomes of the joint activities have to be strictly documented in order to ensure smooth handing over of responsibilities, continuity and sustainability of the partnership. It is for these reasons that ensuring institutional and administrative support is of paramount importance for the success of the partnership. The colleagues from the International Public Health Network also share their experience with facing a serious shortage of project management staff, including accountants.

The greatest challenge before the partnership is reported to be the need for investment of significant time, financial and human resources in order to make an actual and active contribution to the implementation of the activities and the development of the partnership. Otherwise, it will hardly go beyond the formulated set of intentions, documented in the cooperation agreement - a situation frequently faced by many academic partnerships [2]. While in most of the cases, the external funding institutions and foundations are willing to provide resources for the initiation of the partnerships, in the long-term, the universities themselves have to invest resources to maintain the successful collaborations. The relevance of similar joint projects for scientific research and academic training has to be acknowledged, and state financing has to be planned for their development. The more expensive activities like the transnational journeys have to receive additional funding from other sources. In this respect, the organization of the external funding, as in this case from DAAD and the European Commission (through "Erasmus+" programme) should be considered for the expansion of possibilities for additional financing.

The most prevalent perceived barriers to online teaching experienced by various faculty groups at a public institution located in the southeastern United States are determined [3]. Through an exploratory factor analysis, four constructs are identified: i) interpersonal barriers; ii) institutional barriers; iii) training and technology barriers; and iv) cost/benefit analysis barriers.

One hundred Australian undergraduate nursing students undertake 10 international clinical placements offered in the Asian region by eight universities [4]. Five categories related to the aims of the educational programs are identified: 'becoming culturally aware through immersion', 'working with the community to promote health', 
'understanding the role of nursing within the health care setting', 'translating theory into professional clinical practice', and 'developing relationships in international learning environments'. Four categories related to learning outcomes are identified: 'understanding healthcare and determinants of health', 'managing challenges', 'understanding the role of culture within healthcare' and 'demonstrating professional knowledge, skills and behaviour'.

In a qualitative exploratory case study, the perspectives of 26 midwifery educators working in midwifery education institutions in Papua New Guinea is explored in order to assess how capacity building approach uses international partnerships to improve teaching and learning [5]. The study provides insights into strategies which aid institutions and individuals better plan and implement international midwifery partnerships to strengthen context-specific knowledge and skills in teaching.

Within a qualitative descriptive case study at six higher education institutions - two in Finland and one in Croatia, Estonia, the Netherlands and Slovenia each, a convenience sample of 14 mentors, 15 teachers and 14 students with international experiences form six focus groups using a semi-structured questionnaire based on a literature review [6]. Most respondents' recommendations deal with the practical supervision of students as three major themes aer outlined: 'Attitudes towards internationalization of practical placements', 'Factors impacting the international placement experience', and 'Pedagogical methods used and structural support available for internationalization'.

Three hundred sixty-one host students recruited from three medical university partnerships located in Maastricht, the Netherlands, and Doha, Qatar, completed a survey about their motives, transition from high school, language, preparedness for practice, future career planning, and general satisfaction [7]. The students generally hold positive views of the education they receive. Switching to a new language of instruction (English) and learning environment is not perceived as a major obstacle. Despite differences in learning experiences, host students feel the partnership affords opportunities to acquire unique academic competencies and boost their career.

Crossborder curriculum partnerships are a relatively new and fast-growing form of internationalization in which the curriculum already developed by the home institution crosses borders and is implemented in another host institution [8]. Guidance is provided to those considering or engaged in designing, developing, managing, and reviewing a crossborder curriculum partnership or other forms of international educational partnerships in medical education.

The collaborative partnership between Addis Ababa University, Ethiopia, and the University of Toronto, Canada, in which the international partner acts as invited guest is known as the Toronto Addis Ababa Academic Collaboration [9]. From its inception, it has aimed to be relational and has firmly placed ownership of the co-developed curriculum at Addis Ababa University. Other explicit aims are to help Addis Ababa University develop culturally appropriate programming that would be sustainable with local resources as well as to develop capacity-building, co-teaching models.

In 2011, the University of Pittsburgh School of Medicine, the USA, and Tsinghua University, China, form a partnership to further the education of Tsinghua medical students [10]. These students act as visiting research scholars for two years of their eight-year medical degree curriculum. During this time, they work full-time in medical school laboratories and research programs of their choice, essentially functioning as graduate students. In their first two months in Pittsburgh, the scholars have a one-week orientation to biomedical research, followed by two-week rotations in four labs selected on the basis of the scholars' scientific interests, after which they choose one of these labs for the remainder of the two years.

A framework for unifying, systematizing, and improving the quality of international surgical teaching collaborations so that they can better address the global surgical need is determined by a convenience sample of 68 surgeons, anesthesiologists, physicians, residents, nurses, academics, and administrators from the U.S., Canada, and Norway interviewed using a pre-determined set of openended questions [11]. There is a need for a centralized/ systematized process with designated leaders, a universal data bank of current efforts/progress, communication amongst involved parties, full-time administrative staff, dedicated funds, a scholarly approach, increased use of technology, and more research on needs and outcomes.

As an advanced cancer institute in China, Cancer Hospital Chinese Academy of Medical Science attaches great importance to international exchanges and cooperation within graduate medical education [12]. The Department of Epidemiology is involved in several existing international training programs and launches a short-term training program in cooperation with foreign universities and institutes such as Fogarty International Clinical Research Scholars and Fellows Program and FulbrightFogarty Fellowship Program as most typical examples of this collaboration.

\section{CONCLUSION}

As the concern for human health does not recognize national borders, the importance of international perspectives and cooperation in the training of health professionals should always be on the universities agenda. The good practice of academic collaboration meets the needs for modern education for the nursing care specialists from an international perspective but also, from the perspective of the peculiarities of the local context. Partnerships in the field of academic training, including mobility of students and teachers, faces various challenges and is particularly difficult to be maintained as sustainable unless it has sufficient funding.

The comparative analysis suggests that similar partnerships can be applied by other universities with the relevant experience and resources at hand for the provision of training for different health professionals. MU-Varna 
is prepared to take part in such trainings with partner universities and institutions in order to enhance the international cooperation for academic training in the fields of public health and nursing care through university partnerships.

\section{REFERENCES:}

1. Brzoska P, Akgun K, Antia BA, Thankappan KR, Nayar KR, Razum O. Enhancing an international perspective in public health teaching through formalized university partnerships. Front Public Health. 2017 Mar 9;5:36. [PubMed] [Crossref]

2. Battat R, Seidman G, Chadi N, Chanda MY, Nehme J, Hulme J, et al. Global health competencies and approaches in medical education: a literature review. BMC Med Educ. 2010 Dec 22;10:94. [PubMed] [Crossref]

3. Lloyd SA, Byrne MM, McCoy TS. Faculty-perceived barriers of online education. Merlot J Online Learn Teach. 2012 Mar;8(1):1-12.

4. Browne CA, Fetherston CM. How do we facilitate international clinical placements for nursing students: A cross-sectional exploration of the structure, aims and objectives of placements. Nurse Educ Today. 2018 Jul;66:1-7. [PubMed] [Crossref]

5. West F, Dawson A, Homer CSE. Building midwifery educator capacity using international partnerships: Findings from a qualitative study. Nurse Educ Pract. 2017 Jul;25:66-73. [PubMed] [Crossref]

6. Hvaliè-Touzery S, Hopia $\mathrm{H}$, Sihvonen S, Diwan S, Sen S, SkelaSaviè B. Perspectives on enhancing international practical training of students in health and social care study programs - A qualitative descriptive case study. Nurse Educ Today. 2017 Jan;48:40-47. [PubMed] [Crossref]

7. Waterval D, Frambach JM, Scott SM, Driessen EW, Scherpbier AJJA. Crossborder curriculum partnerships: medical students' experiences on critical aspects. BMC Med Educ. 2018 Jun 7;18(1):129. [PubMed] [Crossref]

8. Waterval DGJ, Driessen EW, Scherpbier AJJA, Frambach JM. Twelve tips for crossborder curriculum partnerships in medical education. Med Teach. 2018 May;40(5): 514-519. [PubMed] [Crossref]

9. Whitehead C, Wondimagegn D,
Baheretibeb Y, Hodges B. The international partner as invited guest: beyond colonial and import-export models of medical education. Acad Med. 2018 May 2. [Epub ahead of print] [PubMed] [Crossref]

10. Levine AS, McDonald MC, Bogosta CE. Sino-U.S. partnerships in research, education, and patient care: The experience of the University of Pittsburgh and UPMC. Sci China Life Sci. 2017 Oct;60(10):1150-1156. [PubMed] [Crossref]

11. Fallah PN, Bernstein M. Unifying a fragmented effort: a qualitative framework for improving international surgical teaching collaborations. Global Health. 2017 Sep 7;13(1):70. [PubMed] [Crossref]

12. Rezhake R, Hu SY, Zhao YQ, Zhang L, Zhao XL, Dominguez AZ, et al. Impact of international collaborative training programs on medical students' research ability. J Cancer Educ. 2018 Jun;33(3):511-516. [PubMed] [Crossref]

Please cite this article as: Dokova A. Challenges for the Training of Health Professionals Through International University Partnerships. J of IMAB. 2018 Oct-Dec;24(4):2205-2209. DOI: https://doi.org/10.5272/jimab.2018244.2205

Received: 01/06/2018; Published online: 19/10/2018

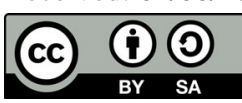

Address for correspondence:

Aneta Dokova, PhD

Department of International Relations, Medical University of Varna

55, Marin Drinov Str., Varna 9002, Bulgaria

E-mail: dokova@mu-varna.bg 